\title{
SARTRE E A REALIDADE HUMANA: UMA COMPREENSÃO FENOMENOLÓGICA DA EXISTÊNCIA DO PARA-SI ENQUANTO LIBERDADE
}

\section{SARTRE AND HUMAN REALITY: A PHENOMENOLOGICAL UNDERSTANDING OF THE EXISTENCE OF THE FOR-ITSELF AS FREEDOM}

Thiago Teixeira Santos*

\section{RESUMO}

A questão da liberdade é, sem dúvida, um dos grandes alicerces da filosofia sartriana. Isso se comprova pela infinidade de estudos que se ocupam desse tema. Para nós, a investigação acerca da liberdade enquanto condição da realidade humana vislumbra uma meta: sua relação com uma suposta moral existencialista em geral, e sartriana em particular.

PALAVRAS-CHAVE: Sartre. Liberdade. Realidade humana. Consciência.

\section{ABSTRACT}

The question of freedom is undoubtedly one of the great foundations of Sartrean philosophy. This is proved by numerous studies dealing with this issue. For us, research about freedom as a condition of human reality envisions a goal: his relationship with a supposed moral existentialist in general and in particular Sartrean.

KEYWORDS: Sartre. Freedom. Human reality. Consciousness.

\section{INTRODUÇÃO}

A questão da liberdade é, sem dúvida, um dos grandes alicerces da filosofia sartriana. Isso se comprova pela infinidade de estudos que se ocupam desse tema. Para nós, a investigação acerca da liberdade enquanto condição da realidade humana vislumbra uma meta: sua relação com uma suposta moral existencialista em geral, e sartriana em particular.

Antes de tudo, é preciso delimitar em qual terreno tratamos da liberdade visto que esse conceito acompanha discussões desde a Grécia antiga. Pois bem, analisamos a questão da liberdade através do existencialismo. Ora, existem duas correntes dessa doutrina filosófica. De qual partimos? Sartre em sua conferência intitulada $O$ existencialismo é um humanismo defende uma vinculação ao chamado existencialismo ateu que, por sua vez, se distancia de

\footnotetext{
* Mestre em Filosofia pela FAJE - Faculdade Jesuíta de Filosofia e Teologia. Professor do Departamento de Filosofia da PUC Minas. E-mail: thiagoteixeiraf@gmail.com.
} 
filósofos como Karl Jaspers e Gabriel Marcel. Estes são conhecidos como existencialistas cristãos. O que distancia essas duas correntes? Os existencialistas de modo geral consideram a existência precedente à essência, ou seja, impõe-se à realidade humana inventar-se. No entanto, a existência de Deus para Sartre não é algo relevante. O filósofo francês parte do que chama de "desespero original" (SARTRE, 2010, p. 61) ou descrença, isto é, se Deus existe ou não, não é o problema, pois o ponto central da discussão consiste em entregar ao próprio homem o encargo sobre sua existência.

Ao considerarmos a criação de um corta-papel, um livro ou um objeto qualquer, precisamos acreditar que o artífice possui previamente os conceitos, bem como a inspiração para fabricar tais objetos. Desse modo, não podemos inferir que um homem produza um corta-papel, um livro, ou o lápis sem considerar a utilidade desses objetos, isto é, a que eles se destinam. Assim concordamos que, a "essência" do corta papel é dada de antemão. Ela é anterior à existência do objeto, pois na medida em que o homem cria esses objetos, sabe para quais fins eles se orientam. O artífice domina a técnica e o conceito e tal relação configura a fórmula. Ele detém a totalidade do objeto, desde sua formalidade até a sua realização concreta. Todas essas informações implicam no que Sartre chama de visão técnica de mundo, segundo a qual a "produção precede a essência". (SARTRE, 2010, p. 24).

Ao conceber a Deus como criador, vinculamo-nos, até certo ponto, a essa perspectiva de artífice, nesse caso, um artífice superior. Sartre entende que o conceito de homem, presente no intelecto divino, seria idêntico ao de corta-papel para um artífice comum. Nesse sentido, o homem realizaria uma série de empreendimentos que estariam dispostos previamente no entendimento divino. O existencialista considera que o ateísmo do século XVIII, embora tenha suprimido a noção de Deus, não extinguiu a pré-existência da essência em face de sua existência. Dito de outro modo: as concepções que permeavam o Iluminismo, mesmo retirando Deus, não dizimaram a noção de natureza humana.

Nesse contexto, o homem seria possuidor de uma natureza encontrada em todos os homens. Sendo assim, cada homem particular seria um exemplo para o todo, o universal. Outrossim, a natureza, isto é, a essência de homem precederia a existência. Na contramão, Sartre se vincula a uma perspectiva ateia. Logo, a pergunta que paira é: Deus existe ou não? Sartre não se preocupa em responder a essa questão, pois o existencialismo que ele defende: 
algum conceito, e que tal ser é o homem, ou como diz Heidegger, a realidadehumana. (SARTRE, 2010, p. 25)

Para o existencialismo ateu que Sartre defende o homem é nada antes de tornar-se. Destarte, ele será algo a partir da existência e será aquilo que se tornar. Assim, o nada surge no mundo através da realidade humana e é a partir dele que ela pode ser tornar aquilo que puder ser. Aproxima-se liberdade e ser para-si, ou melhor, a liberdade desponta na origem desse modo de ser. Ao escapar do modo de ser em-si, através de um lapso interno, se assim podemos colocar, o para-si denota essa liberdade, qual seja, não permanecer encerrado num modo de ser pleno. É pelo para-si que ocorre a nadificação do ser rumo aos seus possíveis. Ele é o ser das possibilidades e, portanto, nele ocorrem a nadificação e a temporalização do ser, ou seja, há nesse modo de ser uma fuga do passado e um lançamento aos projetos futuros.

Afastamo-nos, pois, orientados por Sartre, da preexistência da essência em face da existência e consideramos que a liberdade é o fundamento do ser para-si. Ele, ao surgir não é definido, não está à mercê de nenhuma existência anterior a si. Trata-se de um ser que é abertura. O homem, nessa esteira, cria sua essência a partir da existência, do seu lançamento e desamparo no mundo.

Por ser livre, o para-si, ao surgir, apenas existe, descobre-se no mundo, vazio, uma total indeterminação de si mesmo. No começo, não é nada — apenas uma "possibilidade de ser". A partir dessa pura existência, o homem se faz a si mesmo e cria sua essência. Isso explica o princípio sartriano de que a "existência precede a essência”. (PERDIGÃO, 1995, p. 90).

O homem está “condenado a ser livre” (SARTRE, 2010, p. 33), isto é, não criou a si mesmo e está abandonado no mundo. Não pode recorrer a nada, dentro ou fora de si que lhe dê fundamento. Não dispõe de uma essência originária que sustente suas decisões. É livre, pois a liberdade não é um atributo, mas uma condição ontológica. A partir dessa condição de nada originário o homem constrói a si. Com efeito, ele assume sobre si o inteiro encargo de sua existência e de sua liberdade. Essa ausência de desculpas ou estatutos coloca esse mesmo homem frente à responsabilidade para consigo mesmo e outrem. Cabe-nos, por ora, investigar o conceito de liberdade.

Ser livre, nesse sentido não é ser algo, mas poder escolher ser tudo o que é permitido à realidade humana. As possibilidades se abrem ao ser e permitem que ele seja, pois antes de sua existência não existem fundamentos. Inferimos assim que, o ser ocorre nas possibilidades fazendo a si mesmo. 
Fica-nos claro que o possível é, em certa medida, mais importante que o atual, pois ele orienta o homem a tornar-se, isto é, empreender sua intenção rumo a algo que ele ainda não é, mas pode ser, ou nos dizeres de Franklin Leopoldo e Silva: "um movimento de ser." (LEOPOLDO, 2011, p. 122).

Esse movimento ou projetar do homem rumo ao que pode ser é o que Sartre denomina ser o primeiro princípio do existencialismo, qual seja: "o homem é nada além daquilo que se faz" (SARTRE, 2010, p. 25), em outros termos, afirma-se a subjetividade. Em suma, a liberdade é uma condição ontológica, ou seja, ela ocorre concomitantemente ao para-si. Refere-se à possibilidade de ser da realidade humana a partir do nada que ela é inicialmente nos limites da existência.

\section{O HOMEM É AQUILO QUE SE FAZ: LIBERDADE E PROJETO}

A realidade humana é originalmente nada e se torna algo ao longo da existência. Desse modo, a existência é anterior à essência. Ela será o que se tornar, ou seja, não existe uma natureza humana. Compreende-se que, esse homem não possui estatutos anteriores ou superiores - transcendentes, no sentido em que Deus é transcendente - a ele, mas isso não significa que esse homem pode fazer tudo o que quiser, isto é, seguir seus impulsos de modo arbitrário. Aqui se instaura a discussão acerca do projeto fundamental.

A liberdade não se apresenta, ao menos na filosofia de Sartre, como empreendimento humano realizado a esmo, fazendo o que se quer, importando-se apenas com o seu desejo e desconsiderando os outros. Ao contrário, cada ato humano designa, para nosso autor, uma eleição originária de si. As ações denotam a nossa configuração enquanto homem. Tal escolha não ocorre de modo gratuito uma vez que, a eleição de si se refere a todas as deliberações que o homem sustenta sobre si e que, por conseguinte que afetam a outrem.

A realidade humana, portanto, é aquilo que se projeta. Esse mesmo projeto é a tomada da consciência do possível ou dos possíveis que podem ser alcançados pelo homem. Ele primeiro é indeterminação e é nesse âmbito que a realidade humana se confunde com a liberdade, pois a escolha originária está para a liberdade e seu caráter indeterminado. Isso nos leva a crer que não há nenhum determinismo presente na concepção existencialista de Sartre, pois o homem não está à mercê de possibilidades delineadas, em que ele terá que escolher, mas sua configuração se realiza a partir do nada de ser. Contrapondo livre-arbítrio e liberdade (no sentido sartriano), Franklin Leopoldo esclarece que: 
Por vezes, se entendeu, na filosofia, que a liberdade seria o livre-arbítrio entre duas ou mais possibilidades já previamente determinadas, atitude guiada por critérios por via dos quais o sujeito discerniria, entre os caminhos oferecidos, qual deveria tomar. Mas essa concepção de liberdade preserva o determinismo na medida em que a escolha obedece a normas já estabelecidas e se dá entre possibilidades preestabelecidas. A verdadeira liberdade consiste em inventar a possibilidade, a ação, e o critério pelo qual a adotamos. Não existe uma tabela de valores que cada um pode consultar antes de tomar uma decisão; isso seria a renúncia à liberdade ou a escolha da determinação, uma forma inautêntica de existir, decorrente de que, dentre as opções possíveis, está aquela de agir como se não fosse livre. Entretanto, não se pode renunciar à liberdade: a omissão já é uma escolha. Daí a frase que se tornou célebre: o homem está condenado a ser livre. (LEOPOLDO, 2011, p.122)

A concepção de liberdade para Sartre denota uma radicalidade, pois se une a noção de fatalidade. Sendo assim, a realidade humana é o nada de ser, que se lança para fora num movimento de tornar-se. Nesse contexto ocorre uma transitividade do ser rumo ao que ele quer ser. Esse nada de ser adere a projeto e se movimenta a partir daí, rumo a criar-se. Mas devemos esclarecer que, esse projeto de inventar a si nunca se completa, pois, a realidade humana é um processo inacabável.

Voltando-nos ao projeto fundamental esclarecemos que ele não é inconsciente, isto é, para haver eleição do rumo que se quer, é necessária a consciência. O projeto também não é anterior ao ato, ocorre concomitante ao mesmo e necessita dele para realizar-se. Não ocorre antes do fato, uma vez que não se trata aqui de potência de ato, isto é, de uma motivação anterior ao ato que propicie sua efetivação. Destarte, o projeto fundamental existe no ato, penetra nele e é contemporâneo à sua efetivação. O projeto se dá e, ao mesmo tempo, possibilita as ações, escolhas e emoções do homem. A vida humana em suas múltiplas manifestações expressa, de modo diverso, esse projeto fundamental. Caso a realidade humana não possuísse esse projeto, seus empreendimentos aconteceriam de modo a esmo.

O projeto fundamental, embora busque uma permanência - e isso porque tem por fundamento o ser-para-si que procura retornar a certa plenitude de ser —, nunca se vê total. Dito de outro modo, ele não é imutável, embora tenha certo caráter de permanência, pois a realidade humana que se escolhe e se cria é a mesma, mas as escolhas e os possíveis são os mais diversos. Se o projeto fundamental fosse cristalizado não haveria liberdade, ou seja, caso houvesse destino, a liberdade não poderia coexistir junto à realidade humana. A cristalização do projeto fundamental levaria o homem a se escolher em definitivo o que sucumbiria os 
possíveis que ocorrem em seu ser. A realidade humana, como sabemos, possui a falta de ser como fundamento, ela é uma totalização-em-curso. ${ }^{1}$

A liberdade é a sustentação do projeto, isto é, por ela o projeto se realiza e torna-se um constante nunca acabado. Trata-se de uma abertura como demonstra Cléo Góis em seu artigo intitulado Sartre: da consciência de O ser e o nada ao existencialismo humano:

Sendo essencialmente projeto, isto é, tarefa de se libertar, a liberdade descobre-se "no próprio ato numa unidade com esse ato". (SARTRE, 1943, p. 516). A consciência sartriana, em vez de ser, já que não em essência, deve fazer-se, criar-se, uma vez que é espontaneidade pura, invenção constante. (GÓIS, 2008, p. 74).

A consciência ocorre como projeto que se lança ao futuro. Sendo assim, podemos entendê-la em detrimento apenas do que será. Enxergamos aqui dois pontos importantíssimos: primeiro, o projeto se distancia do passado, isto é, este não é de todo suprimido, mas não é ele que orienta o inventar da realidade humana. O outro ponto relaciona diretamente com o primeiro: a recusa ao determinismo. Não há nada antes desse lançar da consciência. Ela é vazia. Podemos inferir então que o homem é esse ser que vem a si por meio do futuro, pela elaboração de seus fins.

Surgem então algumas questões: Como o projeto se refere ao futuro? A transformação da realidade humana ocorre de que modo? E o presente?

Não há aqui o menor vestígio de supressão do presente. Notamos que Sartre não extingue o presente quando afirma que o homem, em situação, transcende as adversidades objetivas e vislumbra no futuro seus possíveis. Segundo Paulo Perdigão, Heidegger "foi o primeiro pensador a destacar o papel do futuro, observando que o homem se supera sem cessar em direção ao porvir e que estamos sempre adiante de nós mesmos e do mundo, vivendo em função dos possíveis futuros" (PERDIGÃO, 1995, p. 77-78). As concepções de Martin Heidegger, como demonstra Perdigão, nos levam à noção de projeto sob a ótica de Sartre. Para esse autor, a experiência de mundo do homem é marcada pela ida e vinda constante do Ser ao futuro e vice-versa e denomina essa afetação do futuro no presente (como ocorre no contrário) como "circuito da ipseidade". Trata-se da "presença ausente" (SARTRE, 2009, p. 156), isto é, o para-si que se percebe nas lonjuras dos possíveis. Esse circuito denota o movimento da realidade humana que transcende rumo a si mesma.

\footnotetext{
${ }^{1}$ Ao tratar da meta do ser-para-si, Paulo Perdigão identifica que esse modo de ser vislumbra um objetivo, a saber, alcançar a sua estabilidade perdida. Entretanto seu fundamento é a falta de ser e o para-si não alcança esse estado compacto novamente.
} 
Percebemos então a transcendência que possibilita a invenção do ser do homem. Podemos dizer que o mundo é do homem na medida em que nele o projeto, o lançar-se da consciência aos possíveis, acontece. Sendo assim, não podemos negar que estamos frente à estrutura do modo de ser do para-si: o nada. Porque é nadificador, esse modo de ser pode constituir-se num movimento de tornar-se. Num movimento contrário, ou seja, no modo de ser do em-si, há uma totalidade e nenhum vestígio de falta de ser. Desse modo, o mundo e o próprio ser estão para a consciência como passíveis de nadificação como mostra Hadi Rizk em sua obra Comprendre Sartre:

Com a aparição do mundo como fenômeno, o para-si, como relação se revela totalizante, embora essa totalização, em razão das condições que a fazem existir como a nadificação, não pode se fechar em uma totalidade acabada. (RIZK, 2001, p. 77) ${ }^{2}$.

Não obstante a busca da totalização, isto é, do retorno à completude do ser, o para-si se vê frustrado, pois sua estrutura fundamental, isto é, o nada, impede que ele alcance tal objetivo de retorno ao modo de ser em-si. Isto ocorre porque o para-si se funda no nada e esse mesmo nada original que o faz ser das aberturas. Vemos então o real papel da consciência em relação ao mundo: não há motivações anteriores à existência que definam o que o homem deve ser ou fazer, mas a essência será criada, configurada a partir da realidade humana que existe, de modo gratuito, contingente, mas existente. Nesse sentido, cabe ao homem emprestar sentido a sua realidade existencial. Assim entendemos o fluxo do projeto fundamental no tocante a existência humana, pois essa não está encerrada em nenhum determinismo sendo em última instância: invenção. Um esforço perpétuo enquanto o homem existir.

Existimos e nesse movimento de ser, o homem percebe que sua consciência é vazia, isto é, nela encontra-se apenas o futuro como condição de realização do presente. Com efeito, o projeto é lançamento ao futuro para realização hodierna, uma transitividade entre futuro e presente que se realiza e se situa através da ação. "O homem é o ser que vem a si próprio a partir do futuro, que se define por seus fins" (GÓIS, 2008, p. 75).

Identificamos aqui um télos ambivalente: motivação e fracasso. Motivação, pois são os fins que nos propomos enquanto projetos que norteiam esse caminho da existência. $\mathrm{O}$ homem compreende neles sua realidade, sua situação, bem como o campo de adversidades que o cerca, assim, através da tensão, consciência (de) e ação empreendem uma

\footnotetext{
${ }^{2}$ Avec l'apparition du monde comme phénomene, le pour-soi comme rapport s’avère totalisant, quoique cette totalisation, en raison des conditions que la font exister, comme la néantisation ne peut se refemeren une totalité achevée.
} 
transformação factual. Destarte, a consciência que se desprende do presente e se lança ao futuro retorna ao presente a fim de justificá-lo, modificá-lo. O fracasso está no fato de que o fim absoluto, isto é, o desejo maior do para-si não se realiza. Dito de outro modo, jamais esse modo de ser alcança uma plenitude. Na verdade, a intenção visa o que ainda não é e o homem nunca será total.

Toda essa discussão suscitou dois problemas: O primeiro se refere ao momento anterior à adesão ao projeto fundamental, isto é, faz-se necessária uma análise do que Sartre entende como nada e de sua afetação na realidade humana, sua condição livre e a realização de sua escolha originária de si. Na mesma esteira de problematizarão, é preciso verificar o alcance do projeto.

\title{
2 TERRENO PARA INVENÇÃO HUMANA: O NADA
}

\begin{abstract}
O Ser pelo qual o Nada vem ao mundo deve nadificar o Nada em seu ser, e, assim mesmo, correndo o risco de estabelecer o Nada como transcendente no bojo da imanência, caso não nadifique o Nada em seu ser a propósito de seu ser. O Ser pelo qual o nada vem ao mundo é um ser para o qual, em seu ser está a questão o Nada de seu ser: o ser pelo qual o Nada vem ao mundo deve ser seu próprio Nada. E por isso deve-se entender não um ato nadificador, que requisesse por sua vez um fundamento no Ser, e sim uma característica ontológica do Ser requerido. (SARTRE, 2009, p. 65).
\end{abstract}

Tratamos, no início desta dissertação, dos modos de ser. Perguntamos sobre os modos de ser, bem como suas estruturas e articulações e nesse caso inferimos que "se a negação não existisse nenhuma pergunta poderia ser formulada, sequer em particular, a do ser" (SARTRE, 2009, p. 64). Nesse sentido percebemos que a negação é, por excelência, a fonte da interrogação, sobre o mundo e sobre o ser. Para que haja investigação e invenção do ser, como concebemos que ocorre através da perspectiva de Sartre, é preciso que o nada se dê de algum modo.

Seria inviável pensar o nada fora do ser, pois nesse caso a criação de si, num curso, seria absurda. O nada, portanto, ocorre, como afirma nosso autor, no "miolo do ser" (SARTRE, 2009. p. 64). Ele também não pode ser um caminho de suspensão do ser ao infinito de modo abstrato. Tal suspensão fugiria largamente da proposta de Sartre. Ora, onde está o nada e como ele se realiza no ser? No mundo? Entendemos que o Nada está no cerne do ser e assim se dão as negatividades. Mas esse Nada é produzido por qual modo de ser? Através do em-si ou do para-si? O nada não pode surgir do modo de ser do em-si uma vez 
que, ele é pura positividade. Não há a possibilidade das nadificações surgirem por meio de um ser que é maciço e não carece.

Com efeito, sabemos que o nada não pode ser estrutura do ser do em-si, assim como não pode ser afastado do ser e logo nos surge a seguinte questão: Se o nada não pode ser concebido nem dentro, tampouco fora do ser, de onde ele vem? Ao tratarmos dessa questão reconhecemos que somente o ser pode nadificar, mas se instaura aqui outro problema, pois o nada não é. Como resolver essa querela? É-nos permitido falar do nada somente através da aparência de ser, ele possui tal virtualidade de ser, ou melhor, tem para ele mesmo um ser emprestado. Vimos que o ser que dá "corpo" ao nada não pode ser o em-si, pois esse se identifica consigo mesmo. O ser ao qual nos referimos nadifica o nada, ou melhor, é o ser pelo qual o nada vem às coisas. Concluímos que o ser que possibilita a existência do nada e que também o possui como característica ontológica é o para-si.

Percebemos que o nada deve existir através de um ser pelo qual há a interrogação que se lança ao mundo, mas que é capaz de colocar-se também a interrogação. Chegamos, nessa progressão de raciocínio, ao homem ou à realidade humana, uma vez que o homem é esse ser que traz a si mesmo o não ser. Sartre entende que o homem é inicialmente nada e por isso não pode ser definido. Caso afirmássemos uma predeterminação — ou conceito ou essência que dissesse a realidade humana antes de sua existência contingente - nos vincularíamos a um tipo de essencialismo que, por sua vez, possuiria larga distância em relação ao pensamento de Sartre. Este entende que, por ser o nada a realidade originária do homem, isto é, sua estrutura ontológica, esse mesmo homem se definirá através dessa constatação de existência, como esclarece:

\footnotetext{
Queremos definir o ser do homem na medida em que condiciona a aparição do nada, ser que nos apareceu como liberdade. Assim, condição exigida para nadificação do nada, a liberdade não é uma propriedade que pertença entre outras coisas à essência do ser humano. Por outro lado, já sublinhamos que a relação entre existência e essência não é igual no homem e nas coisas do mundo. A liberdade humana precede a essência do homem e torna-a possível: a essência do ser humano acha-se em suspenso na liberdade. Logo, aquilo que achamos liberdade não pode se diferençar do ser da "realidade humana". O homem não é primeiro para ser livre depois: não há diferença entre o ser do homem e seu "ser-livre". Portanto, não se trata aqui de abordar de frente questão que só pode ser tratada exaustivamente à luz de rigorosa elucidação do ser humano; precisamos enfocar a liberdade em conexão com o problema do nada e na medida estrita em que condiciona a aparição deste. (SARTRE, 2009, p. 68)
}

A negação surge no mundo pelo homem, isto é, através dele o mundo é nadificado, desvelado e descoberto. Todavia, considerar que o homem é o meio pelo qual o Nada surge 
nos direciona a outra questão, qual seja: O que é o homem, para que seu ser possibilite o surgimento do nada? Para tanto, devemos estabelecer uma digressão em nosso estudo e suspender a questão da liberdade novamente.

No processo de geração de si, ou movimento de ser, o homem é capaz de pôr-se em questão, ou seja, colocar-se "fora de seu ser, e ao mesmo tempo debilitar a estrutura de seu ser" (SARTRE, 2009, p 67). Isso nos leva a considerar que o homem deve empreender sua nadificação para além do nada, isto é, rumo à outra possibilidade de ser ele mesmo: a liberdade.

O homem não é primeiro para ser livre depois. A liberdade, para Sartre, não é uma dádiva, um atributo dado à humanidade, pois ela é a sua própria existência. Existência e liberdade, nesse caso, se confundem. O nada e a liberdade fazem parte da constituição humana, ou seja, inicialmente nada, o homem se configurará de modo livre, não porque se quer livre, mas sim porque ele é a sua liberdade. Essa liberdade é objetiva, não se refere a uma dimensão interior do homem, ou uma escolha entre dois possíveis apenas. Ela diz respeito ao homem que está situado no mundo, isto é, uma vez que a realidade humana não pode ser vista desgarrada do mundo a liberdade, que é o Ser do homem, ocorre nesse mesmo mundo. Entendemos que Sartre demonstra o homem e sua afirmação realizada, isto é, sua liberdade em situação, no mundo. Ele é aquilo que fizer como aponta Cardoso:

Eis que o sujeito assume o papel de protagonista na reflexão de Sartre. Aquilo que se faz vem antes, e determina aquilo que se é. A ação, pois, ocupa o primeiro lugar dentro de uma reflexão que enquadra em seu aspecto intencional. A intenção do sujeito é o interesse de Sartre. (CARDOSO, 2005, p. 205).

De fato Sartre parte da subjetividade e a entende como esse inventar-se a si mesmo como característica fundamental do homem, tendo em vista sua contingência, isto é, seu ser lançado e desamparado no mundo. Ele é mesmo seu protagonista, na medida em que traz a si todo o encargo de existir. Não há escusas, nada que o defina nem dentro, tampouco fora de si. Nenhuma essência é plasmada no homem de modo a configurá-lo, determiná-lo antes de sua existência. Ele tem em suas mãos o encargo de inventar, criar sua essência a partir de sua intenção, ou seja, sua escolha original objetivada nas ações.

Ao interligar o nada, a liberdade e existência humana, Sartre suplantou todo o determinismo, ou seja, não há fundamento para as ações, decisões e intenções humanas preexistentes, tudo é criado a partir da existência do homem no mundo. Nosso autor considera que a realidade humana e seus empreendimentos acontecem num "fluxo temporal" (SARTRE, 
2009, p. 77) e nele o homem realiza perpetuamente sua identidade consigo mesmo. Há uma efetivação da liberdade em todo desdobramento existencial toda vez que a realidade humana é confrontada, isto é, a liberdade se efetiva na medida em que supera e transcende um constrangimento objetivo e se refaz, a partir dali, ex nihilo e livremente. Desse modo estamos entregues a nós mesmos e totalmente responsáveis por nossa existência, bem como com a figuração de um universo humano. A realidade que se interpõe entre Nada, liberdade e existência, é reconhecida por Sartre como angústia.

A angústia é, em Sartre, a consciência dessa situação de desamparo e liberdade do homem. Ela também é vista como estrutura existencial na medida em que é a consciência que o homem possui de sua liberdade. Nesse caso poderia haver um determinismo psicológico? De modo algum, pois a liberdade se confunde com a angústia, isto é, essa mostra-se como sua consciência.

Ela, a angústia, é revelada pela liberdade e se estrutura, sob o prisma de Sartre, através do nada que se interpõe entre os motivos e os atos. Isso é o projeto fundamental que fora explorado anteriormente é marcado por motivos realizados. O projeto é empreendido através das escolhas. O homem é um projeto que se vive, posteriormente faz a si mesmo. Tudo o que realiza é um desdobramento de um projeto originário que é maior que uma mera vontade. Nesse sentido o homem é absolutamente responsável pelo que é como afirma Reynolds em sua obra Existencialismo:

É importante reconhecer que, para Sartre, essa liberdade de ser determinado, esse
reconhecimento de que somente nós conferimos significado a um despertador de
manhã, de que somente nós decidimos o que é moral ou não, de que somente nós
decidimos nosso próprio futuro (ou ao menos seu significado), envolve uma pesada
responsabilidade. Na verdade, é parcialmente por essa razão que ele sugere que a
humanidade está condenada a ser livre, pois assumimos a inteira responsabilidade
pelos eventos que nos sobrevêm, uma vez que nós construímos para estarmos aí
nessa situação, com nossas capacidades particulares ou não, e retemos nossa
capacidade de negar nossa facticidade. (REYNOLDS, 2013, p. 104).

Nesse sentido, o homem assume total responsabilidade por si e por outrem na medida em que configura uma imagem de homem em alcances universais. $\mathrm{O}$ universal concreto, por ora, não é nosso objetivo. O que pretendemos salientar nesse momento é o Nada como estrutura humana que possibilita a efetivação da liberdade que, por sua vez, é a própria realidade humana. Com efeito, o verdadeiro terreno para que o homem se coloque frente a si mesmo e se construa dá-se através da nadificação. 
A falta de estatutos pelos quais o homem possa saber previamente como agir coloca-o frente a sua angústia. Com efeito, ele estará sempre diante de sua possibilidade. Aqui está sua angústia. No entanto, cabe esclarecer que não é a angústia que realiza os possíveis, mas as ações humanas. Ela é, em última instância, somente o reconhecimento da possibilidade como possibilidade humana, ou seja, quando a consciência se vê distante de sua essência, isto é, o nada, e separada do futuro pela liberdade que ela é. Isso significa que um Nada nadificador deixa o homem sem desculpas na medida em que o projeto futuro está sempre nadificado e reduzido à categoria de possibilidade, uma vez que o futuro ainda está fora do alcance humano.

Colocamos o homem numa perspectiva temporal. O futuro é uma espécie de encontro consigo mesmo que vai além do presente, desta data, deste mês ou hora. A angústia é vista por Sartre, como o temor de não se achar nesse futuro, ou então como os atos que, ocorridos pela liberdade total da existência humana, revelam as possibilidades humanas. Há, nessa segunda perspectiva, um comprometimento, uma ação e uma intenção de inventar-se enquanto homem.

O homem não possui nenhum tipo de apoio, nem auxílio: é, como vimos, originalmente nada. Destarte, ele está numa condenação de sua liberdade, ou seja, nos limites do paradoxo de Sartre. Sua existência é contingente. Está desamparado no mundo e sem fundamentos que delimitem previamente o que ele será, pois sua essência será definida, como sabemos, posteriormente à sua existência. Sendo assim, o futuro é virgem, isto é, está aberto ao fazer. Logo, o homem será o que fizer surgir, o que realizar de si mesmo no terreno de seu lançamento no mundo, sem escusas.

Sartre entende a responsabilidade total do homem ante sua existência que, por sua vez, coloca-o frente a frente com a angústia oriunda desse peso de existir. O sentido da existência humana surge através dos empreendimentos, decisões e ações humanas que realizaram, num movimento constante de ser. Nessa constante o homem decifrará e dará sentido, ao mesmo tempo, à sua vida. Sendo assim, carpinteiro, revolucionário ou proletário, o homem será aquilo que escolher e realizar para si mesmo. O homem é aquele que escolhe, em última instância, a si mesmo e ao outro, como um legislador que tem para si uma larga e profunda responsabilidade. Isso traz à realidade humana a angústia, como entende Góis:

É essa co-responsabilidade que dá fundamento à angústia, pois cada indivíduo é um legislador pronto a escolher a si próprio e a humanidade inteira, não podendo escapar a essa sua total e profunda responsabilidade. Mas nem para Sartre a 
liberdade equivale a libertinagem. Liberdade absoluta só existe para um projeto fundamental, para a escolha originária, a escolha absolutamente incondicionada. Todas as outras escolhas são condicionadas pela escolha originária, a qual, no entanto, pode ser modificada. A modificação do projeto inicial é possível a qualquer momento: "A angústia que, quando revelada, manifesta à nossa consciência a liberdade atesta a modificabilidade perpétua de nosso projeto inicial" (1943, p. 8082). Estamos constantemente ameaçados de termos anuladas nossa escolha atual, constantemente ameaçados de nos escolher e nos tornar assim diferentes do que somos. Tudo que acontece no mundo remonta à liberdade e à responsabilidade da escolha originária. (GÓIS, 2008, p. 72).

Ao tratarmos do nada enquanto estrutura basilar da condição humana, devemos nos ater à questão dos possíveis e da radicalidade em que Sartre entende a responsabilidade do homem consigo mesmo e com outrem. Sublinhamos aqui o desamparo que, para Sartre, tem por companhia a angústia. $\mathrm{O}$ desamparo diz respeito ao mundo dos possíveis que se abre ao homem a partir de sua facticidade. Desse modo, o homem só pode se apoiar em sua vontade ou no conjunto de probabilidades que permeiam e tornam sua ação possível. Assim sendo, percebemos que angústia e desamparo são oriundos desse Nada originário no que concerne a ordem humana, no entanto, não sustenta nessa mesma ordem um quietismo, tampouco um pessimismo, pois o homem é chamado, por sua própria condição, a criar-se a si mesmo, e isso não é nada mais que um otimismo existencialista. Há um niilismo afirmativo nessa perspectiva que se instaura pela angústia. Ela é o caminho para que o homem tome consciência da liberdade que ele mesmo é.

\footnotetext{
Essa angústia não nos separa da ação, mas faz parte da própria ação: "É na angústia que o homem toma consciência de sua liberdade" (SARTRE, 1943, p. 66-67) ou, dito de outro modo, a angústia é o modo de ser da liberdade como consciência de ser. A liberdade que descobrimos na angústia, que é a angústia de mim mesmo, caracteriza-se pelo nada que se insinua entre os motivos e o ato, e carrega consigo um fundamento de niilização, uma vez que a angústia é também captação do nada. (GÓIS, 2008, p. 72).
}

Destarte, angústia é para o homem a consciência de sua liberdade de condição, ou seja, ele se angustia, pois vê-se lançado e intimado pela sua realidade a criar-se a si mesmo, bem como a criar imagem de homem que afete sua inteira época. A realidade humana está constantemente, através do projeto original, frente a não-ser, isto é, o Ser se lança rumo ao que ainda não é para criar-se e justificar-se. Entre nada e ato se interpõe uma ação constitutiva do homem em favor de si mesmo.

Podemos inferir que qualquer que seja a constituição do homem, isto é, o que surgir a partir de sua existência e de sua escolha por si, emerge daquilo que esse Ser ainda não é. O 
nada que reside no seio do ser do para-si, não se refere a uma negação gratuita da realidade objetiva, mas visto como condição de possibilidade, ou seja, ele é o meio pelo qual o homem transcende rumo ao que se fizer. É nesse sentido que nosso autor afirma que o nada vem ao mundo pelo homem, ou seja, pela liberdade;

\begin{abstract}
O homem é livre porque não é si mesmo, mas presença a si. O ser que é não poderia ser livre. A liberdade é precisamente o nada que tendo sido no âmago do homem e obriga a realidade humana a fazer-se em vez de ser (...) para a realidade humana, ser é escolher-se: nada the vem de fora, ou tampouco de dentro, que ela possa receber ou aceitar. Está inteiramente abandonada, sem qualquer ajuda de nenhuma espécie, à insustentável necessidade de fazer-se até o mínimo detalhe. Assim, a liberdade não é um ser: é o ser do homem, ou seja, seu nada de ser. (SARTRE, 2009, p. 545).
\end{abstract}

Nesses termos, o homem não é em-si, ou seja, não pode ser apreendido, ou melhor, não pode apreender-se na totalidade. Não é um ser maciço. Isso significa que, no bojo de sua realidade, de sua condição está o nada que, por sua vez, possibilita a escolha de si mesmo e a transcendência responsável de si rumo a si mesmo. Ele não é essa totalidade, pois, é livre, faltante. Caso contrário, se fosse pleno, seria absurdo buscar nele mesmo momentos, transições, escolha, uma vez que seria preenchido de si numa afirmação total. Dito de outro modo, seria escravo de si e não sua liberdade.

Em suma, percebemos que a liberdade é para Sartre a condição basilar da realidade humana e que, a partir dessa constatação, o homem se inventa, tendo em vista os motivos e ações. Assim o homem se vê radicalmente responsável pelo que faz de si mesmo e da imagem humana que reverbera em seu tempo. Nesses termos, o homem vê-se desamparo, pois está sem chão predefinido onde possa se apoiar e, então, é incitado a viver sua liberdade, criar sentido e constituir valores num universo estritamente humano. O nada, portanto, é visto por Sartre como essência da liberdade nesse elã existencial. Por meio dele, o homem se lança aos possíveis, uma vez que ele mesmo é o Ser dos possíveis. Nessa esteira, encontramos os dois conceitos fundamentais para adentramos no campo de uma proposta moral nos limites do pensamento sartriano: ação e responsabilidade.

\title{
CONCLUSÃO
}

Ao vincularmo-nos à perspectiva de Sartre acerca da realidade humana, fica evidente sua relação intrínseca com a liberdade. Ora, como isso se realiza? Em primeira instância, devemos constatar que a liberdade corresponde à própria existência humana. Ela não se 
determina como uma dádiva ou um dom cedido ao homem. Isso nos soaria bastante essencialistas. Ao contrário, a liberdade é o bojo da existência humana que, situada, se lança rumo à constituição de seu projeto e, mais, se torna responsável pela instauração do valor de sua existência, bem como do mundo humano que criará a seu redor.

A condição humana, isto é, o modo de ser do para-si denota movimento. Assim, percebemos que há no homem um fluxo. Este, por sua vez, é ocasionado pela consciência que se coloca sempre à distância de si. Sendo assim, o homem é o ser das lonjuras ou das ações possíveis.

Em Sartre, constatamos que a existência humana é um movimento constante de nadificação e transvaloração. Deste modo, o homem se torna amplamente responsável por suas ações, visto que não há nenhuma tábula de valores ou essência que anteceda a sua existência. Assim, a liberdade - eixo central da filosofia sartriana — indica que o homem é absolutamente responsável pelo que faz de si mesmo e pelo modo com que afeta a outrem.

Não raro, liberdade e escolha se engrazam. O homem será aquilo que escolher. Nesse sentido, percebemos uma relação intrínseca entre escolha, ação, liberdade e responsabilidade que, para nós, indicam o início de uma investigação moral nos limites epistemológicos do existencialismo sartriano.

\section{REFERÊNCIAS}

ALVES, Igor S.; JACOBELIS, Paola G.; BELO Renato; SOUZA, Thana de Souza. O drama da existência: Estudos sobre o pensamento de Sartre. São Paulo: Humanitas, 2003.

ANDRADE, Abrahão Costa. Militante da Liberdade. As comemorações do centenário de nascimento de Jean Paul Sartre reavivam o interesse pelo pai do existencialismo ateu. Discutindo filosofia, São Paulo, ano. 1, nº 1. p. 32-37.2005.

BARBOSA, Elyana. Jean-Paul Sartre, o Filósofo da Esperança. In: CESAR, Marcondes Constança; BULCÃO, Marly (Org.). Sartre e seus contemporâneos: Ética, racionalidade e imaginário. São Paulo: Idéias\& Letras, 2008, p.9-16.

BEUVOIR, Simone de. Por uma moral da ambiguidade. Rio de Janeiro: Nova Fronteira, 2005.

BENNY, Lévy. O testamento de Sartre. Porto Alegre: L\&PM, 1986.

BOLLONOW, Otto Fiedrich. Filosofia existencial. Coimbra: Arménio Amado, 1946.

BORNHEIM, Gerd Alberto. Debates de filosofia: Sartre, Metafísica e Existencialismo. São Paulo: Perspectiva, 1984. 
CARDOSO, Delmar. A liberdade em L'être et le néant: Descrição e problemas. Síntese. Revista de filosofia, Belo Horizonte, n.103, 2005, p. 203-218.

COHEN-SOLAL, Annie. Sartre. Porto Alegre: L\&PM, 1986.

COLETTE, Jaques. Existencialismo. Porto Alegre: L\&PM, 2009.

ETCHEVERY, Auguste. O conflito atual dos humanismos. Porto: Tavares Martins, 1946.

FIGURELLI, Roberto. Sartre e a literatura engajada. Revista Letras, Curitiba, n.36, 1987, p.89-111.

GÓIS, Cléa. Sartre: da consciência do Ser e o Nada ao Existencialismo é um humanismo. In: CESAR, Marcondes Constança; BULCÃO, Marly (Org.). Sartre e seus contemporâneos. Ética, racionalidade e imaginário. São Paulo: Idéias \& Letras, 2008.

HEIDEGGER, Martin. Ontologia: hermenêutica e facticidade. Tradução de Renato Kirchner. Petrópolis: Vozes, 2012.

HEIDEGGER, Martin. Ser e Tempo. 2v.12.ed. Petrópolis: Vozes, 2002.

HEIDEGGER, Martin. Sobre o Problema do Ser: o caminho do campo. São Paulo: Livraria Duas Cidades, 1969.

JEANSON, Francis. Le problème morale et le pensée de Sartre. Paris: Seuil, 1965.

KANT, Immanuel. Fundamentação da metafísica dos costumes. Tradução Tania Maria Bernkopf. São Paulo: Abril Cultural, 1980 (Coleção Os Pensadores).

KIERKEGGARD, Soren. O conceito de angústia: uma simples reflexão psicológicodemonstrativa direcionada ao problema dogmático do pecado original. Tradução de Álvaro Luiz Montenegro Valls. Rio de Janeiro: Vozes, 2001.M

LANDSBERG, Paul-Louis. O sentido da ação. Tradução Maria Helena Kühner. Rio de Janeiro: Paz e Terra, 1968.

LEOPOLDO E SILVA, Franklin. Ética e literatura em Sartre: ensaios introdutórios. São Paulo: UNESP, 2004.

LEOPOLDO E SILVA, Franklin. O Imperativo Ético de Sartre. In: NOVAES, Adauto (Org.). O silêncio dos intelectuais. São Paulo: Companhia das Letras, 2006. 151-160.

LEOPOLDO E SILVA, Franklin. O conhecimento de si. Rio de Janeiro: Casa da Palavra: São Paulo: Casa do Saber, 2011.

MARCONDES, Constança Cesar; BULCÃO, Marly (Org). Sartre e seus contemporâneos. Ética, racionalidade e imaginário. São Paulo: Idéias \& Letras, 1998. 
MENDONÇA, Cristina Diniz. O Mito da resistência. Tese de Doutorado. São Paulo: USP, 2001.

MESZAROS, Istvan. A obra de Sartre: busca da liberdade. São Paulo: Ensaio, 1991.

MORAVIA, Sérgio. Sartre. Tradução de José Eduardo Rodil. São Paulo: Martins Fontes, 1970.

MOUTINHO, Luiz Damon. Sartre: Existencialismo e Liberdade. São Paulo: Moderna, 1995.

MÜLLER, Marcos. A má-fé e a teoria da negação em Sartre. Manuscrito, V, n.2, Campinas, 1982.

MÜNSTER, Arno. Sartre et la morale. Paris: L'Harmattan, 2007.

NOUDELMANN, F.; PHILIPPE, G. Dictionnaire Sartre. Paris: Champion, 2004.

PERDIGÃO, Paulo. Existência \& liberdade: uma introdução à filosofia de Sartre. Porto Alegre: L\&PM, 1995.

PFIEL, Claudio Luis. Moral em Sartre: uma porta para o possível. In: CESAR, Marcondes Constança; BULCÃO, Marly (Org.). Sartre e seus contemporâneos. Ética, racionalidade e imaginário. São Paulo: Idéias\& Letras, 2008. p.147-161.

POVOAS, Jorge Freire. A Má-fé na Analítica Existencial Sartriana.In: CESAR, Marcondes Constança; BULCÃO, Marly (Org.). Sartre e seus contemporâneos. Ética, racionalidade e imaginário. São Paulo: Idéias\& Letras, 2008.p. 161-199.

REYNOLDS, Jack. Existencialismo. Tradução: Cesar Souza. Petrópolis: Vozes, 2013.

RIZK, Hadi. Comprendre Sartre. Paris: Armand Colin, 2011.

SANTOS, Magda Guadalupe dos. Alteridade, Facticidade e igualdade: leituras de Sartre, Beauvoir e Levinas no processo de radicalização da Metafísica no século XX. In: OLIVEIRA, Ibraim Vitor de; SANTOS, Magda Guadalupe dos (Org). Tempos da Metafísica. Belo Horizonte: Tessitura, 2011, p. 53-93.

SARTRE, Jean-Paul. A imaginação. Tradução Paulo Neves. Porto Alegre: L\&PM, 2008.

SARTRE, Jean-Paul. Anarquia e moral. Entrevista de Jean-Paul Sartre concedida a R. Fornet-Betancourt,M. Casañas e A. Gomes. Concordia, Espanha, nº1, p. 75-77. 1982.

SARTRE, Jean-Paul. A transcendência do ego: esboço de uma descrição fenomenológica. Tradução de João Batista Kreuck. Rio de Janeiro: Vozes, 2013.

SARTRE, Jean-Paul. Crítica da razão dialética: precedido por Questões de Método. Rio de Janeiro: DP\&A, 2002. 
SARTRE, Jean-Paul. Diário de uma guerra estranha. Tradução Aulyde Soares Rodrigues e Guilherme João de Freitas Teixeira.2.ed.Rio de Janeiro: Nova Fronteira 2005.

SARTRE, Jean-Paul. Esboço de uma teoria das emoções. Porto Alegre: L\&PM, 2010.

SARTRE, Jean-Paul. O existencialismo é um humanismo. Tradução João Batista Kreuch. Petrópolis: Vozes, 2010.

SARTRE, Jean-Paul. O ser e o nada: Ensaio de ontologia fenomenológica.18.ed.Petrópolis: Vozes, 2009.

SARTRE, Jean-Paul. Verdade e existência. Tradução Marcos Bagno. Rio de Janeiro: Nova Fronteira, 1990.

SARTRE, Jean-Paul. Situações I. Lisboa: Europa-America, 1968.

SCHELER, Max. Da reviravolta dos valores. Tradução Marco Antônio dos Santos Casanova. Petrópolis: Vozes, 1994.

SIRINELLI, Jean-François. Jean-Paul Sartre, um intelectual engajado. In NOVAES, Adauto (Org.). O silêncio dos intelectuais. São Paulo: Companhia das Letras, 2006, p.161-169.

SOUZA, Thana Mara de. Sartre e a literatura engajada. São Paulo: Editora da Universidade de São Paulo, 2008.

TROGO, Sebastião. O impasse da má-fé na moral de J. P. Sartre. Belo Horizonte: Ciência Jurídica, 2011. 